\title{
Importance of Mycoplasma hominis in acute salpingitis assessed by culture and serological tests
}

\author{
K LIND,* G B KRISTENSEN, $\uparrow$ A C BOLLERUP, $\neq$ P LADEHOFF, $\uparrow$ S LARSEN, $\uparrow$

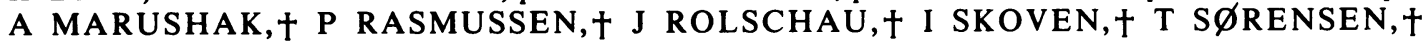 \\ AND I LIND‡ \\ From the *Mycoplasma Laboratory and the $¥$ Neisseria Department, Statens Seruminstitut, Copenhagen, \\ and the +Department of Obstetrics and Gynaecology, University Hospital, Odense, Denmark
}

SUMMARY In 95 women with a provisional diagnosis of pelvic inflammatory disease, a final diagnosis of acute salpingitis was confirmed by laparoscopy in 46 and 10 had strong clinical evidence of acute salpingitis. The findings in the remaining 39 patients without signs of acute salpingitis by laparoscopy were used as a standard of reference. Criteria for the diagnosis of possible mycoplasmal salpingitis were tentatively defined as the isolation of Mycoplasma hominis from the cervix together with positive test results for $M$ hominis antibodies (a titre of $>1 / 1280$ or a change in titre, or both); these criteria were fulfilled in 12 patients with acute salpingitis. A positive correlation between mycoplasmal salpingitis and chlamydial salpingitis or gonococcal salpingitis, or both, was significant. Mycoplasmal salpingitis was not associated with any characteristic clinical feature different from those of patients with non-mycoplasmal salpingitis. Our findings do not support the view that $M$ hominis is an important primary pathogen in acute salpingitis.

\section{Introduction}

Although Chlamydia trachomatis and Neisseria gonorrhoeae have been shown to be aetiologically important in acute salpingitis, the role of Mycoplasma hominis as a primary cause has not been convincingly established. ${ }^{1-5}$

The aim of this study was to evaluate the importance of $M$ hominis in acute salpingitis by cultural and serological procedures. This evaluation was based on findings in 95 women who attended a gynaecological department and in whom a provisional clinical diagnosis of acute pelvic inflammatory disease (PID) was made. ${ }^{6}$ The results of cultures and serological tests for infection with $C$ trachomatis and $N$ gonorrhoeae in the same study population have been reported separately. ${ }^{6}$

\section{Patients and methods}

\section{STUDY POPULATION}

During one year 95 women were admitted to a gynaecological department with symptoms suggestive of

Address for reprints: $\operatorname{Dr} \mathbf{K}$ Lind, Mycoplasma Laboratory, Department of Clinical Immunology, Statens Seruminstitut, Amager Boulevard 80, DK-2300 Copenhagen S, Denmark

Accepted for publication 7 November 1984
PID. ${ }^{7}$ All except 10 were submitted to laparoscopy on the day of admission. In 46 the diagnosis of acute salpingitis was confirmed by laparoscopy and graded according to Weström ${ }^{8}$ as mild in 16 , moderate in 10 , and severe in 20 . Ten patients in whom laparoscopy had to be omitted had strong clinical evidence of acute salpingitis. In 39 patients who had no signs of acute salpingitis on laparoscopy the diagnoses were: acute appendicitis (2), ectopic pregnancy (5), ovarian cyst (10), retrograde menstrual bleeding (1), hydrosalpinx or peritubal adhesions with no signs of actual or recent infection (7), and no abnormal findings (14). These 39 women served as a standard of reference.

Patients with acute salpingitis did not differ significantly from those without acute salpingitis with regard to age, history of a PID or gonorrhoea, or both, or use of oral contraceptives.

\section{CULTURAL PROCEDURES}

Specimens from the cervix and the urethra were taken from 92 patients on admission and again after one and two weeks, or before the patient was discharged from hospital. The specimen for the culture of $M$ hominis and $N$ gonorrhoeae was taken on a single charcoal impregnated cotton swab and transported by mail in Stuart's medium. The transportation time did not exceed 24 hours. After inoculation on 
the medium used for culture of gonococci ${ }^{6}$ the swab was inoculated into classic Hayflick's medium ${ }^{9}$ using agar plates, and broth containing $1 \%$ arginine; $M$ hominis was identified by a disc growth inhibition test $^{10}$ using a rabbit antiserum to the PG21 strain.

Specimens for culture of $M$ hominis were taken at laparoscopy from the fallopian tubes of 25 patients with acute salpingitis and 21 without salpingitis, as described for culture of $N$ gonorrhoeae. ${ }^{6}$

\section{INVESTIGATION OF ANTIBODIES}

Antibodies to $M$ hominis were investigated by an indirect haemagglutination test ${ }^{11}$ using glutaraldehyde treated sheep erythrocytes sensitised with the diluted sonicate of $M$ hominis cells harvested from a 24 hour culture in Hayflick's medium. ${ }^{9}$ Two genital strains (H27 and SC4, from Ruth Lemcke, Institute for Research on Animal Diseases, Compton, UK) were used as antigens. These two strains were chosen because their antigens had given different titres with some of the serum samples tested preliminarily. Furthermore, maximum titres obtained with these antigens were on average eight times higher than titres obtained when the classic laboratory strain PG21 was used as antigen (Lind $K$, unpublished observation). All serum samples were absorbed with unsensitised erythrocytes and then diluted twofold from 1/20 in triplicate in a microtitre assay using two rows for erythrocytes sensitised with the two antigens and one for unsensitised erythrocytes. Anti-H27 and anti-SC4 rabbit serum samples were incorporated in each assay as tests for reproducibility. When titres obtained with the two antigens differed, the highest titre was recorded.

At least two blood specimens were taken at intervals of one week from all patients with acute salpingitis except one, on average 3.5 per patient. Only one specimen could be obtained from 10 of the 39 patients without acute salpingitis, because they were discharged within one week. ${ }^{6}$ In this group the average was $2 \cdot 2$ specimens per patient.
PATIENTS WITH CHLAMYDIAL AND GONOCOCCAL SALPINGITIS

Criteria of chlamydial salpingitis and gonococcal salpingitis were established as described elsewhere. ${ }^{6}$ By these criteria 22 of the $\mathbf{4 6}$ patients with laparoscopically verified acute salpingitis were classified as having chlamydial salpingitis, three as having gonococcal salpingitis, four as having chlamydial and gonococcal salpingitis, and 17 as having nonchlamydial, non-gonococcal salpingitis. Of the 10 patients diagnosed only clinically as having acute salpingitis, three had chlamydial, two chlamydial and gonococcal, and five non-chlamydial, non-gonococcal salpingitis.

\section{STATISTICAL METHODS}

Non-parametric (Wilcoxon's, $\chi^{2}$, and Fisher's) statistical tests were used to evaluate differences, and p $<0.05$ was considered to be significant. The predictive values of positive and negative tests were calculated according to Wulff, ${ }^{12}$ as described elsewhere. 6

\section{Results}

\section{CULTURE}

Table I shows that $M$ hominis was isolated from 46 $(50 \%)$ of the 92 patients investigated by culture. In all 46 both the urethra and the cervix harboured this mycoplasma. No other large colony mycoplasma species was isolated.

Specimens for the culture of $\boldsymbol{M}$ hominis were taken from the urethra and the cervix of 55 of the 56 patients with acute salpingitis and were positive in 31 $(56 \%)$. A similar percentage was found in $25(54 \%)$ of the 46 patients whose acute salpingitis had been laparoscopically confirmed. Of the 39 patients without acute salpingitis, 37 were investigated and 15 $(41 \%)$ gave positive results. As table I shows, $M$ hominis was isolated more often from patients with chlamydial or gonococcal salpingitis, or both, than from those with non-chlamydial, non-gonococcal

TABLE I Distribution of 95 patients with regard to culture of $M$ hominis and positive* serological test results for antibodies to $M$ hominis

\begin{tabular}{|c|c|c|c|c|c|c|}
\hline \multirow[b]{2}{*}{ Diagnosis } & \multicolumn{6}{|c|}{ No (\%) positive/No investigated by: } \\
\hline & \multicolumn{2}{|c|}{ Culture } & \multicolumn{2}{|c|}{$\begin{array}{l}\text { Serological } \\
\text { test }\end{array}$} & \multicolumn{2}{|c|}{$\begin{array}{l}\text { Culture and } \\
\text { serological test }\end{array}$} \\
\hline $\begin{array}{l}\text { Acute salpingitis: } \\
\text { Chlamydial, gonococcal, or both } \\
\text { Non-chlamydial, non-gonococcal }\end{array}$ & $\begin{array}{r}24 / 33 \\
7 / 22\end{array}$ & $\begin{array}{l}\text { (73) } \\
\text { (32) }\end{array}$ & $\begin{array}{r}13 / 34 \\
2 / 22\end{array}$ & $\begin{array}{l}(38) \\
(9)\end{array}$ & $\begin{array}{r}10 / 33 \\
2 / 22\end{array}$ & $\begin{array}{r}(30) \\
(9)\end{array}$ \\
\hline Total & $31 / 55$ & (56) & $15 / 56$ & (27) & $12 / 55$ & (22) \\
\hline No salpingitis & $15 / 37$ & (41) & $3 / 39$ & (8) & $1 / 37$ & (3) \\
\hline
\end{tabular}

*Maximum titre of antibodies to $M$ hominis $\geqslant 1 / 1280$, appreciable change to or from $\geqslant 1 / 320$, or both. 
TABLE II Distribution of patients with chlamydial or gonococcal salpingitis, both, or neither and of patients without salpingitis with regard to maximum titres of antibodies to Mycoplasma hominis

\begin{tabular}{|c|c|c|c|c|c|c|c|c|c|c|c|}
\hline \multirow[b]{2}{*}{ Group of patients } & \multicolumn{11}{|c|}{ No of patients with maximum titres of: } \\
\hline & $\leqslant 1 / 20$ & $1 / 40$ & $1 / 80$ & $1 / 160$ & $1 / 320$ & $1 / 640$ & $1 / 1280$ & $1 / 2560$ & $1 / 5120$ & $\geqslant 10000$ & Total \\
\hline \multirow{2}{*}{$\begin{array}{l}\text { Chlamydial or gonococcal } \\
\text { salpingitis, or both } \\
\text { Non-chlamydial, non-gonococcal } \\
\text { salpingitis } \\
\text { No salpingitis }\end{array}$} & 9 & & 1 & 3 & 2 & 7 & 4 & 6 & & 2 & 34 \\
\hline & $\begin{array}{r}9 \\
12\end{array}$ & $\begin{array}{l}1 \\
6\end{array}$ & 2 & $\begin{array}{l}3 \\
4\end{array}$ & $\begin{array}{l}3 \\
5\end{array}$ & $\begin{array}{l}3 \\
6\end{array}$ & 1 & $\begin{array}{l}1 \\
2\end{array}$ & & & $\begin{array}{l}22 \\
39\end{array}$ \\
\hline Total & 30 & 7 & 6 & 10 & 10 & 16 & 5 & 9 & & 2 & 95 \\
\hline
\end{tabular}

salpingitis $(p=0 \cdot 006)$ or those without salpingitis $(p=0 \cdot 013)$. It was isolated from similar numbers of patients with non-chlamydial, non-gonococcal salpingitis and those without salpingitis.

$M$ hominis was not isolated from any of the specimens taken from the salpinx.

\section{SEROLOGICAL TESTS}

Table II shows the distribution of maximum titres of antibodies to $M$ hominis in the four groups of patients with acute salpingitis. Antibodies were generally found at a high titre in all groups of patients. A maximum titre of $\geqslant 1 / 160$ was found in 52 $(55 \%)$ out of all patients. Titres below $1 / 1280$ occurred in similar numbers of patients with and without salpingitis, while titres $\geqslant 1 / 1280$ were more common in patients with acute salpingitis $(p<0 \cdot 05)$.

If a titre of $\geqslant 1 / 1280$ defines a positive result, then the predictive value of a positive result for acute salpingitis was $81 \%$ and the predictive value of a negative result for the absence of salpingitis was $46 \%$.

A fourfold or more change in titre of antibodies to $M$ homonis to or from $\geqslant 1 / 320$ during the course of disease was found in seven patients with salpingitis (five with chlamydial or gonococcal salpingitis, or both, and two with non-chlamydial, non-gonococcal salpingitis) but in none of the patients without salpingitis $(p=0.04)$. Only one patient showed a rise to a titre below 1/320; this was a patient with chlamydial salpingitis in whom the titre rose to $1 / 80$.

If a positive test result was defined as a titre of antibodies to $M$ hominis of $\geqslant 1 / 1280$ or a change in titre to or from $\geqslant 1 / 320$, or both, then $15(27 \%)$ of the 56 patients with acute salpingitis and three $(8 \%)$ of the 39 patients without salpingitis were seropositive, a difference that was significant $(p=0.03)$. If this comparison was based on patients subjected to laparoscopy only, then $13(28 \%)$ of 46 patients with acute salpingitis were seropositive $(p=0 \cdot 03)$. Among patients with acute salpingitis positive results occurred more often in those with chlamydial or gonococcal salpingitis, or both, than in those with non-chlamydial, non-gonococcal salpingitis $(p=0.03)$. The incidence of seropositive results was the same in patients with non-chlamydial, nongonococcal salpingitis and those without salpingitis. The predictive value of a positive result (titre $\geqslant 1 / 1280$ or change, or both) as an indication of acute salpingitis was $83 \%$, whereas that of a negative result indicating the absence of acute salpingitis was $47 \%$.

\section{CULTURE AND SEROLOGICAL TESTS}

A positive culture and a positive serological test result (titre $\geqslant 1280$ or change, or both) (table I) were found in $12(22 \%)$ of 55 patients with acute salpingitis (in $10(22 \%)$ out of 45 in whom it was laparoscopically verified), but in only one (3\%) of 37 without salpingitis $(p<0.05)$. The latter patient had a ruptured ovarian cyst and a history of acute salpingitis two months before admission. The predictive value of these simultaneously positive results (of culture plus serological tests) for acute salpingitis was $92 \%$ (91\% in patients whose diagnosis was confirmed laparoscopically), and the predictive value of simultaneously negative results for the absence of salpingitis was $46 \%(49 \%)$. For these reasons we tentatively designated patients that fulfilled both criteria as having mycoplasmal salpingitis.

\section{CLINICAL FINDINGS}

We recorded various factors known to predispose for salpingitis, such as insertion of an intrauterine device (IUD), abortion, delivery, and various gynaecological procedures. Such factors were more often recorded among patients with acute salpingitis $(17 / 56)$ than among those without salpingitis $(5 / 39)(p<0.05)$. Table III shows, however, that neither predisposing factors nor known previous attacks of salpingitis were more common in patients with than in patients without mycoplasmal salpingitis. Neither was the severity of salpingitis (as estimated by the gradings: mild, moderate, or severe, by the duration of illness before the admission to hospital, or by the time in hospital) influenced appreciably by findings indicating mycoplasmal salpingitis in any of the groups with acute salpingitis. Again, if infection with $M$ hominis was diagnosed by an appreciable change 
TABLE III Clinical variables in 55 patients with acute salpingitis and 30 with chlamydial salpingitis with and without mycoplasmal salpingitis

\begin{tabular}{|c|c|c|c|c|}
\hline \multirow[b]{2}{*}{ Clinical variables } & \multicolumn{2}{|c|}{$\begin{array}{l}\text { No with acute salpingitis } \\
\text { in whom indications of } \\
\text { mycoplasmal salpingitis* were }\end{array}$} & \multicolumn{2}{|c|}{$\begin{array}{l}\text { No with chlamydial salpingitis } \\
\text { in whom indications of } \\
\text { mycoplasmal salpingitis }\end{array}$} \\
\hline & $\begin{array}{l}\text { Present } \\
(n=12)\end{array}$ & $\begin{array}{l}\text { Absent } \\
(n=43)\end{array}$ & $\begin{array}{l}\text { Present } \\
(n=9)\end{array}$ & $\begin{array}{l}\text { Absent } \\
(n=2 l)\end{array}$ \\
\hline \multicolumn{5}{|l|}{ Predisposing factors: } \\
\hline $\begin{array}{l}\text { Yes } \\
\text { No }\end{array}$ & $\begin{array}{l}4 \\
8\end{array}$ & $\begin{array}{l}14 \\
29\end{array}$ & $\begin{array}{l}2 \\
7\end{array}$ & $\begin{array}{r}9 \\
12\end{array}$ \\
\hline \multicolumn{5}{|l|}{ Previous salpingitis: } \\
\hline $\begin{array}{l}\text { Yes } \\
\text { No }\end{array}$ & $\begin{array}{l}6 \\
6\end{array}$ & $\begin{array}{l}16 \\
27\end{array}$ & $\begin{array}{l}5 \\
4\end{array}$ & $\begin{array}{r}5 \\
16\end{array}$ \\
\hline \multicolumn{5}{|l|}{ Severity of salpingitis: } \\
\hline Mild and moderate & 5 & 28 & 3 & 12 \\
\hline Severe & 7 & 15 & 6 & 9 \\
\hline \multicolumn{5}{|l|}{ Duration of illness before admission: } \\
\hline $0-7$ days & 6 & 30 & 5 & 11 \\
\hline$>7$ days & 6 & 13 & 4 & 10 \\
\hline \multicolumn{5}{|l|}{ Duration of stay in hospital: } \\
\hline 1-14 days & 7 & 36 & 5 & 16 \\
\hline$>14$ days & 5 & 7 & 4 & 5 \\
\hline
\end{tabular}

* Positive culture and positive serological test result.

in titre of the specific antibodies only, as was seen in seven patients with acute salpingitis, these cases could not be identified by any of the above clinical variables. This evaluation was made separately both for all patients with acute salpingitis and for those with chlamydial salpingitis, as the clinical course of chlamydial salpingitis had been shown to be different from that of gonococcal and non-chlamydial, nongonococcal salpingitis. ${ }^{6}$

\section{Discussion}

$M$ hominis was found to colonise the urethra and the cervix of half the patients in this study, and the difference in isolation rates between patients with and patients without salpingitis was not significant. However, significantly more patients with chlamydial or gonococcal salpingitis, or both, were colonised with this mycoplasma than those with nonchlamydial, non-gonococcal salpingitis or those without salpingitis, which indicates that these sexually transmitted organisms commonly coexist. In other studies $\boldsymbol{M}$ hominis was also isolated from about half of patients with PID. ${ }^{13} 14$

Our finding of $M$ hominis antibody titres of $\geqslant 1 / 160$ in $55 \%$ of all patients (table II) contrasts with the incidence of such titres found in other people not incorporated in this study. In $17 \%$ of serum samples from 149 healthy pregnant women and $24 \%$ of 72 samples from healthy blood donors of both sexes aged under 35 titres were $\geqslant 1 / 160$. Furthermore, only one out of 36 children aged 3 to 10 who were admitted to hospital to undergo adenoidectomy had a titre of $1 / 160$. (Lind $K$, unpublished observation). Of the 52 patients in this study who had titres of anti- bodies to $M$ hominis of $\geqslant 1 / 160$ (table II), 11 still had a titre of $\geqslant 1 / 160$ on re-examination between $21 / 2$ and $71 / 2$ months after the acute illness. This indicates that stimulation of antibody production may persist for months after illness. Titres cannot be compared with those in other studies because different serological techniques and antigens were used. Serological cross reactions between this mycoplasma and other agents have not been reported to our knowledge.

The noticeable association between the presence of chlamydial or gonococcal salpingitis, or both, and the evidence of mycoplasmal salpingitis (table I) might be due to colonisation with $M$ hominis of the urethra and the cervix only. In the 15 culture positive patients without salpingitis, however, none had a rise of titre and only one had a titre of $\geqslant 1 / 1280$. These results indicate that a positive culture plus positive serological test result is associated with acute salpingitis rather than with uncomplicated cervical colonisation with $M$ hominis. These findings may be explained, however, by epithelial damage caused by micro-organisms other than $M$ hominis facilitating the contact between $M$ hominis and the iramune system of the patient, and do not prove that $M$ hominis is a pathogenic micro-organism. Our finding that neither the presence of mycoplasmal salpingitis, according to the tentatively established criteria, nor a change in titre of antibodies to $M$ hominis were associated with any characteristic clinical feature not found when these criteria were absent, indicates that $M$ hominis did not play a major part in the diseases of our patients. In their study of PID, Eschenbach $e t$ al found a significant correlation between $M$ hominis and $N$ gonorrhoeae both on culture and on serological tests, but the report does not state whether 
there was a similar correlation between $M$ hominis and $C$ trachomatis. ${ }^{4}$ Mårdh et al found a rise in titres of antibodies to both chlamydiae and mycoplasmas in four of 60 patients with acute salpingitis. ${ }^{15}$

Mфller et al have argued that PID affecting mainly the parametria could be overlooked at laparoscopy, as the tubes in these patients may appear to be normal. ${ }^{14}$ They found it likely that, if only clinical criteria were used for the diagnosis PID (as in their study), a higher proportion of cases of PID due to infection with $M$ hominis would be included. In our study none of the 85 patients investigated by laparoscopy had any signs of parametritis without salpingitis. If such patients had been overlooked in the group without salpingitis, where they might represent cases of infection with $M$ hominis, they should have been found among the 21 patients who, at laparoscopy, had hydrosalpinx or peritubal adhesions without signs of actual or recent infection or no abnormal findings (see Patients and methods). Of these patients, nine fulfilled the criteria of PID proposed by M $\phi$ ller et al. ${ }^{14} \mathrm{M}$ hominis was isolated from only three of the nine, and the geometric mean titre of antibodies to $M$ hominis was no higher $(1 / 86 \cdot 4)$ than that of the whole group without salpingitis $(1 / 85 \cdot 9)$. None of them had an appreciable change in titre. These findings indicate that parametritis caused by infection with $M$ hominis was not very likely to occur among our patients without salpingitis.

$M$ hominis was not recovered from any of the 46 specimens from the salpinx, of which 25 were from patients with acute salpingitis. They were taken from the fimbrial end, so this finding does not exclude colonisation by $M$ hominis in a more medial part of the salpinx. Mårdh and Weström isolated $M$ hominis from the fallopian tube in four of 50 patients with acute salpingitis. ${ }^{13}$ Sweet et al failed to isolate $M$ hominis from the fallopian tube of 26 women with acute salpingitis, of whom 19 had mycoplasmal colonisation of the endocervix.

In the report published here and another report on this study population ${ }^{6}$ we focused on three pathogens as possible causes of acute salpingitis well aware that other pathogens may be causative agents..$^{1-416} \mathrm{~A}$ fourth agent, Ureaplasma urealyticum, was investigated only by culture (Lind $\mathrm{K}$ et al, unpublished observation from this study), and we found no proof that it played any part in acute salpingitis. Of 92 patients, $75(82 \%)$ yielded cultures of $U$ urealyticum. Differences between isolation rates from all the groups of patients were not significant, nor were there any differences in the quantity of ureaplasmas recovered. It was provocative but inconclusive that in the only two patients from whose tubes $U$ urealyticum was isolated this was the sole isolate, and none of the criteria of chlamydial, gonococcal, or mycoplasmal salpingitis were fulfilled.

We conclude that $M$ hominis may have some role in acute salpingitis, especially in cases associated with $C$ trachomatis and $N$ gonorrhoeae, but the aetiological importance of this mycoplasma has not been clarified. Our findings do not support the view that $M$ hominis is an important primary pathogen in acute salpingitis.

The study was supported in part by grant No 552-967 from the Danish Medical Research Council. We thank L Hansen, S O Larsen, and Professor Dr J Ipsen for their help, advice, and statistical calculations.

\section{References}

1. Holmes KK, Eschenbach DA, Knapp JS. Salpingitis: overview of etiology and epidemiology. Am J Obstet Gynecol 1980; 138:893-900.

2. Mårdh P-A. An overview of infectious agents of salpingitis, their biology, and recent advances in methods of detection. $A m$ J Obstet Gynecol 1980; 138:933-51.

3. Taylor-Robinson D, McCormack WM. Medical progress. The genital mycoplasmas (first of two parts). $N$ Engl J Med 1980; 302: 1003-9.

4. Eschenbach DA, Buchanan TM, Pollock HM, et al. Polymicrobial etiology of acute pelvic inflammatory disease. $N$ Engl J Med 1975;293: 166-71.

5. Thompson SE, Hager WD, Wong $\mathrm{K}-\mathrm{H}$, et al. The microbiology and therapy of acute pelvic infammatory disease in hospitalized patients. Am J Obstet Gynecol 1980; 136:179-86.

6. Kristensen $\mathrm{GB}$, Bollerup $\mathrm{AC}$, Lind $\mathrm{K}$, et al. Infections with Neisseria gonorrhoeae and Chlamydia trachomatis infections in women with acute salpingitis. Genitourin Med 1985;61: 179-84.

7. Jacobson L, Weström L. Objectivized diagnosis of acute pelvic inflammatory disease: diagnostic and prognostic value of routine laparoscopy. Am J Obstet Gynecol 1969; 105: 1088-98.

8. Weström L. Effect of acute pelvic inflammatory disease on fertility. Am J Obstet Gynecol 1975; 121:707-13.

9. Hayflick L. Tissue cultures and mycoplasmas. Tex Rep Biol Med 1965;23 suppl 1:285-303.

10. Stanbridge E, Hayflick L. Growth inhibition test for identification of Mycoplasma species utilizing dried antiserumimpregnated paper discs. J Bacteriol 1967;93:1392-6.

11. Cho HJ, Ruhnke HL, Langford EV. The indirect hemagglutination test for the detection of antibodies in cattle naturally infected with mycoplasmas. Can J Comp Med 1976; 40:20-9.

12. Wulff HR. Rational diagnosis and treatment. An introduction to clinical decision-making. 2nd ed. Oxford: Blackwell Scientific Publications, 1981:80-102.

13. Mårdh P-A, Weström L. Tubal and cervical cultures in acute salpingitis with special reference to Mycoplasma hominis and T-strain mycoplasmas. British Journal of Venereal Diseases 1970;46: 179-86.

14. Mфller BR, Mårdh P-A, Ahrons S, Nüssler E. Infection with Chlamydia trachomatis, Mycoplasma hominis, and Neisseria gonorrhoeae in patients with acute pelvic inflammatory disease. Sex Transm Dis 1981;8: 198-202.

15. Mårdh P-A, Lind I, Svensson L, Weström L, Møller BR. Antibodies to Chlamydia trachomatis, Mycoplasma hominis, and Neisseria gonorrhoeae in sera from patients with acute salpingitis. British Journal of Venereal Diseases 1981; 57:125-9.

16. Sweet RL, Mills J, Hadley $\mathrm{KW}$, et al. Use of laparoscopy to determine the microbiologic etiology of acute salpingitis. Am J Obstet Gynecol 1979; 134:68-74. 